\section{Stalking - a contemporary challenge for forensic and clinical psychiatry}

\author{
J. H. KAMPHUIS and P. M. G. EMMELKAMP
}

\author{
Background Stalking is causing \\ pervasive and intense personal suffering \\ and is an area of psychiatry that is \\ currently overlooked.
}

\begin{abstract}
Aims To review demographic and clinical characteristics of stalkers as well as the psychological consequences for victims of stalking.
\end{abstract}

\begin{abstract}
Method A Medline and PsycLit search was conducted on stalking, forensic psychiatry, personality disorders, de Clérambault syndrome and erotomania, with respect to the relevance of the articles selected for stalking.
\end{abstract}

Results Stalkers are best thought of as a heterogeneous group whose behaviour can be motivated by different forms of psychopathology, including psychosis and severe personality disorders.

\section{Conclusions There is a clear need to arrive at a consensus on a typology of stalkers and associated diagnostic criteria. The effectiveness of psychological and pharmacological treatments have not yet been investigated. Treatment may need to be supplemented with external incentives provided by the legal system.}

\section{Declaration of interest None.}

Stalking gained major media attention by the often-spectacular accounts of celebrity stalking. Well-known cases from the United States include the stalkers of Madonna and Jodie Foster. However, repeated intrusive communication and harassment is by no means limited to fans targeting the rich and famous. Much more common is the scenario in which stalker and 'stalkee' had some sort of 'real' prior relationship: they were often prior acquaintances or intimates, but professional contacts can also give rise to stalking later (e.g. by clients of psychiatrists or lawyers; or by rejected job applicants).

Forensic psychiatry has given scant attention to the phenomenon of stalking. Few studies have investigated the psychological make-up of stalkers, and to date only one study (Pathé \& Mullen, 1997) has reported on the psychological impact of stalking on its victims. There are no reports of the development of any specific treatment programmes, either for stalkers or for their victims. This article aims to give an overview of stalking and its clinical ramifications.

\section{CURRENT DEFINITION}

Partly as a result of publications in the media on stalking of celebrities, research into marital violence, and anti-stalking laws in some countries, mental health workers have recently started to study stalkers. It became apparent that a proportion of stalkers suffered from erotomania. Originally, erotomania (or de Clérambault's syndrome) was a term reserved for women who held the delusional belief that a man, typically of a higher social class or social esteem, was deeply in love with them. However, a delusional disorder of the erotomanic type, as it is currently classified in DSM-IV (American Psychiatric Association, 1994), only accounts for a very limited subset of episodes of stalking; stalking can result from many different motivations and constellations of psychopathological symptoms.
As often found with recently developed behavioural concepts, there is no consensus about the exact definition of stalking. Most of the disagreement seems to centre on the degree of emphasis placed on the extent to which the stalking evokes a subjective sense of threat. Generally, the various definitions have the following elements in common: (a) a pattern of intrusive behaviour, akin to harassment; (b) an implicit or explicit threat that emanates from the behavioural pattern; and (c) as a result, the target experiences considerable real fear (Meloy, 1998). In this article we use Meloy and Gothard's definition: "Stalking is typically defined as the wilful, malicious, and repeated following or harassing of another person that threatens his or her safety" (Meloy \& Gothard, 1995, p. 258).

\section{NATURE AND PREVALENCE OF STALKING}

Stalking behaviour typically consists of intrusive following of a 'target': for example, by placing one's self in front of the target's home, or other unexpected and unwelcome appearances in their private domain. Stalkers most often persecute their targets by unwanted communications, which can consist of frequent (often nightly) telephone calls, letters, e-mail, graffiti, notes (e.g. left on the target's car), or packages (e.g. gifts, pictures). Somewhat more extreme forms include ordering goods and services in the victim's name and charging to the victim's account, placing false advertisements or announcements, ordering funeral wreaths, spreading rumours about the victim, starting numerous frivolous law suits, smearing the victim's home or destroying or moving their property, threatening the victim with violence, or actually attacking them. Stalkers sometimes involve third parties, which leads to victimisation by association of their family, friends, colleagues, lawyers, psychiatrists or psychologists, etc. Stalking can be of brief duration, but it can also last for many years. Research from the United States shows that in slightly over half the cases, stalking ceases within one year, while in one-quarter of the cases it lasts for 2-5 years (Tjaden \& Thoenness, 1997).

In some cases, the violence may escalate until the stalker actually murders the victim and/or his/her children. In the United States, it is estimated that between $21 \%$ and $25 \%$ of forensic stalking cases culminate in significant violence (Harmon et al, 
1995; Meloy \& Gothard, 1995). The incidence of murder or manslaughter in stalking cases in the United States is estimated at $2 \%$ (Meloy, 1996). Fritz (1995) showed that $90 \%$ of women killed by their exhusband had previously been stalked. These numbers should probably not be extrapolated unreservedly to the European situation: for one reason, because of differences in the availability and possession of firearms.

Obtaining reliable data regarding the prevalence and incidence of stalking is a formidable international problem. Inconsistent definition and demarcation of the concept is partly responsible for this state of affairs. In some European countries stalking by itself is not considered a distinct legal offence which compounds the problem of monitoring and tracking cases for both police and forensic researchers. As a result, estimates of prevalence and incidence are based on very few, predominantly American studies. The US National Violence Against Women Survey contacted 8000 women and 8000 men by telephone, and asked them about stalking experiences (Tjaden \& Thoenness, 1997): $8 \%$ of the women and $2 \%$ of the men had been stalked at some point in their life. This research also illustrates that criminal stalking cases merely reflect the tip of the iceberg: only $50 \%$ of stalking cases were reported to the police, of which $25 \%$ led to an arrest, and only $12 \%$ resulted in criminal prosecution.

Some research has focused on the prevalence of stalking within specific groups. Among 178 randomly sampled American university counselling centre professionals, one in every 18 therapists reported having been harassed or stalked by a previous or current patient (Romans et al, 1996).

In sum, there is a great international need for systematic monitoring of stalking cases, based on some consensual definition, to arrive at reliable estimates of the magnitude of the problem.

\section{THE STALKER}

Meloy (1996) reviewed the (10) empirical studies that had been conducted over the previous 25 years. Up to 1992, empirical research was limited to case reports or smallscale, uncontrolled studies $(n<10)$ on erotomania. Five important empirical studies have been published since (Zona et al, 1993; Mullen \& Pathé, 1994; Meloy \&
Gothard, 1995; Harmon et al, 1995; Mullen $e t a l, 1999)$, all conducted from forensic settings. The findings suggest the following tentative profile of the 'typical' stalker: a single or divorced man in his thirties, often unemployed, of above-average intelligence, with a criminal and psychiatric history. However, the overall (composite) sample does not represent the more ordinary (non-criminal) stalking cases. The attrition at each step of the sequence: stalking complaint-police report-arrest-criminal prosecution, makes it at least doubtful whether the entire spectrum of stalkers is adequately represented. Stalkers form a heterogeneous group with widely different psychopathological motivations, and it is unlikely that the erotomanic stalker, the psychopathic stalker and the 'other cluster B stalker' can be treated equally.

\section{Typology of stalkers}

Several authors have proposed stalker typologies (Zona et al, 1993; Harmon et al, 1995; Wright et al, 1996; Mullen et al, 1999) based on purported psychological characteristics of the stalker and/or the relationship between the stalker and the victim. Most authors agree on the importance of the distinction between stalking in the context of (some sort of) prior relationship and stalking where there has not been a real relationship at all; but they differ in the details of subdivision.

Zona et al (1993) distinguished the following stalkers: (a) the 'classic' erotomanic stalker, who is usually a woman with the delusional belief that an older man of higher social class or social esteem is in love with her; (b) the love-obsessional stalker, who is typically a psychotic stalker targeting famous people or total strangers; and, most common, (c) the simple obsessional stalker, who stalks after a 'real' relationship has gone sour, leaving him with intense resentment following perceived abuse or rejection. Wright et al (1996) present a slightly different classification. They distinguish the domestic stalker and the nondomestic stalker: the former is comparable to Zona et al's 'simple obsessional stalker', whereas the non-domestic stalker comes in two types: the organised stalker and the delusional stalker. The delusional stalker corresponds with Zona et al's 'erotomanic stalker' and 'love obsessional stalker'. The organised stalker targets previously unknown persons through anonymous communication. The victims usually have no knowledge of the identity of the stalker. Finally, Mullen et al (1999) distinguish five types of stalkers: (a) the rejected stalker, who has had a relationship with the victim and who is often characterised by a mixture of revenge and desire for reconciliation; (b) the stalker seeking intimacy, which includes individuals with erotomanic delusions; (c) the incompetent stalker - usually intellectually limited and socially incompetent individuals; (d) the resentful stalker, who stalks to frighten and distress the victim; and finally (e) the predatory stalker, who is preparing a sexual attack. In addition to these categories, there are reports on the so-called 'false victimisation syndrome', during which the 'victim' pretends to have been stalked, by pursuing herself, in order to gain attention (Pathé et al, 1999).

There is a clear need to derive a consensus on a typology of stalkers, with associated diagnostic criteria. At present, there is no evidence that one proposed typology is superior to another. The typology eventually agreed upon should have clear implications for treatment.

\section{Personality of stalkers}

To date, no systematic research has investigated the motivations and personality of stalkers. Reconciliation and reunion on the one hand $v$. revenge and intimidation on the other, are frequently mentioned as motivating stalkers. Tjaden \& Thoenness (1997) found that stalkers' most common motivation was the desire to maintain control over their victims. Again, it deserves mention that most of these findings are based on stalking cases associated with 'romantic relations gone sour'. Reflections on the personality and intrapsychic functioning of stalkers are predominantly psychodynamic in nature, and are focused on the simple obsessional subgroup. The central feature in these theories is an intense narcissistic reaction to rejection and loss, in combination with borderline defence mechanisms such as splitting, initial idealisation, subsequent devaluation, projection and projective identification. The stalker is thought to defend him/herself against intense feelings of humiliation, shame and sadness by narcissistic rage, during which he/she starts devaluing and torturing the love object to maintain the narcissistic linking fantasy (Meloy, 1996).

A related perspective is to describe the stalker's dynamics from the point of view of pathological mourning: stalkers cannot 
adequately process the traumatic object loss, and as a result cannot move on to build new connections, and thus they remain 'stuck'. Several authors have proposed that attachment pathology underlies the disturbed behaviour. Most notably, Meloy (1998) has formulated a tentative model which assigns to attachment pathology the pivotal role in developing stalking behaviours. Some evidence consistent with this line of theorising comes from inspection of stalkers' childhood histories and life-events which immediately preceded stalking. For example, Kienlen (1998) found that a large proportion of stalkers had experienced significant discontinuity in their childhood (e.g. loss of a carer) and that many incidences of stalking immediately follow object loss.

Despite considerable effort (e.g. Dietz et al, 1991a,b; Meloy, 1997; Mullen et al, 1999), the current body of evidence is insufficient for the accurate prediction of stalking cases and of subsequent violent behaviour (including murder). Some stable risk factors have been identified: a history of (domestic) violence, psychiatric history, antisocial personality disorder and a criminal record. An expert witness testimony predicting violence is not to be recommended, given the current shortage of research data. This statement signals no more than one of the most urgent and difficult problems in forensic psychiatry: how to predict dangerousness.

\section{THE STALKER'S VICTIM}

Numerous movies (e.g. Fatal Attraction, Play Misty for Me), documentaries and books give (often quite dramatic) accounts of the experience of being harassed, followed or stalked. The 'typical' victim of stalking is a woman of approximately the same age as the stalker, with whom he previously had a superficial relationship (Meloy, 1996). Another frequent and particularly pernicious scenario is stalking following a history of domestic violence (Kurt, 1995; Walker \& Meloy, 1998). Research by Wilson \& Daly (1993) shows that the probability of getting killed by a spouse is $2-4$ times as great after a divorce or separation than when continuing to live together.

It is not hard to imagine that months or years of exposure to persecution and threats can lead to serious psychological consequences. In particular, it is the constancy of threat into the private domain that causes the greatest distress to victims of stalking. The protracted and intense sense of intrusion and violation, by definition without an escape haven, is what seems to set stalking distress apart from other more or less traumatic types of stress. However, there is a remarkable lack of solid data on victim psychomorbidity following stalking. In their sample of stalking victims, Pathé \& Mullen (1997) found predominantly depression, anxiety and traumatic psychomorbidity. On the basis of self-reports, $37 \%$ of the respondents qualified for a diagnosis of post-traumatic stress disorder (PTSD). This percentage is much the same as the proportion of PTSD cases in victims of domestic violence, which varies from $40 \%$ to $60 \%$ between different studies (Holtzworth-Munroe et al, 1998). Hall (1998) found that victims of stalking perceived personality changes in themselves as a result of the ordeal they had suffered. Increases in caution, suspiciousness, anxiety and aggression were noted most frequently.

Victims of stalking also reacted by making significant changes in their social and professional life (Pathé \& Mullen, 1997). Nearly all victims adjusted their daily routines (routes, habits), and a majority took additional safety precautions such as getting a secret telephone number, house alarm, etc. Four out of ten stalking victims changed their job or moved away in order to escape the stalking terror. About half reported a partial or total loss of productivity (work or study) and decreased social activity. The perceived lack of safety also led many to carry weapons, including firearms.

\section{DIAGNOSTIC ASSESSMENT}

As was emphasised earlier, stalking describes a behavioural problem, not a psychiatric classification per se. Several authors have reflected on the diagnostic assessment of stalkers, and generally made a distinction between psychotic stalkers (Axis I) and stalkers with severe personality pathology (Axis II). The psychotic stalker can exhibit primary erotomania, but erotomanic delusions can also result from multiple other DSM-IV disorders, including schizophrenia, bipolar disorder, and major depression (American Psychiatric Association, 1994). Stalking is predominantly associated with cluster B personality pathology (narcissistic and borderline personality disorders) and to a lesser extent with dependent, schizoid, and paranoid features. There are relatively few reports of stalking by classic psychopaths, and these cases are almost without exception extensions of (long) histories of domestic violence. In addition to these primary disorders, comorbid conditions, such as substance abuse or dependence and affective disorders, are frequently mentioned (Zona et al, 1993; Harmon et al, 1995; Meloy \& Gothard, 1995; Mullen et al, 1999). It is worth noting that almost all diagnostic hypotheses were based on clinical impressions from uncontrolled studies. Controlled research into personality characteristics and psychopathology (based on, for example, structured interviews and standard personality inventories) is sorely lacking.

\section{TREAT MENT OF STALKERS}

Since research into the treatment of stalkers is notably absent, there are no clear guidelines for treatment. The best methods of opposition to, and treatment of, stalking will depend on the stalker's idiosyncratic psychological profile. Erotomanic or otherwise psychotic stalkers will prove to be extraordinarily resistant to treatment. Primary erotomanic delusions are typically unflagging, which leads one to believe that investment in legal means for deterring such stalkers would probably be the most efficient. Involuntary commitment, trespassing orders and street prohibitions are among the options available in several European countries. Unfortunately, such interventions often appear to incense the stalkers and stimulate them to even more malicious and intense persecutory behaviour. To stop stalking in secondary erotomania, the treatment will have to focus on the underlying disorder, and probably involve neuroleptics. Neither of these types of stalker is likely to benefit from psychotherapy. However, the third and most prevalent group consists of obsessed, rejected stalkers with (usually) severe personality disorder; and this group is likely to be best served with a mix of judicial and psychotherapeutic interventions.

A primary problem in treating stalkers is to motivate them for therapy. By the very nature of the problem, stalkers are unlikely to report themselves for psychiatric or psychological treatment. In sum, there is a clear need for controlled studies into the 
effectiveness of psychotherapy and drug therapy for stalkers.

Primary prevention should receive more attention in one particular subset of stalking cases. As discussed, a large proportion of stalking cases follows from histories of domestic violence (Kurt, 1995). Earlier intervention in domestic violence and family counselling can promote a more satisfactory end to relationships and thus prevent subsequent resentment spilling over in stalking.

\section{REFERENCES}

American Psychiatric Association (1994) Diagnostic and Statistical Manual of Mental Disorders (4th edn, revised) (DSM-IV). Washington, DC: APA

Dietz, P. E., Matthews, D. B., Van Duyne, C., et al (1991a) Threatening or otherwise inappropriate letters to Hollywood celebrities. Journal of Forensic Sciences, 36, 185-209.

_ , _ , Martell, D., et al (1991b) Threatening or otherwise inappropriate letters to members of the United States Congress. Journal of Forensic Sciences, 36 1445-1468

Fritz, J. P. (1995) A proposal for mental health provisions in state anti-stalking laws. Journal of Psychiatry \& Law, 23, 295-318.

Hall, D. M. (1998) The victims of stalking. In The Psychology of Stalking: Clinical and Forensic Perspectives (ed. J. R. Meloy), pp. I13-137. San Diego, CA: Academic Press.

Harmon, R., Rosner, R. \& Owens, H. (1995)

Obsessional harassment and erotomania in a criminal court population. Journal of Forensic Sciences, $\mathbf{4 0}$ $188-196$.

Holtzworth-Munroe, A., Smutzler, N., Jouriles, E. N., et al (1998) Victims of domestic violence. In Comprehensive Clinical Psychology, Volume 9 (eds A. S. Bellack \& M. Hersen), pp. 325-339. Oxford: Pergamon.

Kienlen, K. K. (1998) Developmental and socia antecedents of stalking. In The Psychology of Stalking: Clinical and Forensic Perspectives (ed. J. R. Meloy). San Diego, CA: Academic Press

Kurt, J. L. (1995) Stalking as a variant of domestic violence. Bulletin of the American Academy of Psychiatry and the Law, 23, 219-230.

Meloy, J. R. (1996) Stalking (obsessional following): A review of some preliminary studies. Aggression and Violent Behaviour, I, 147-162.

- (1997) The clinical risk management of stalking: "someone is watching over me. ...". American Journal of Psychotherapy, 5I, 174-184.

\section{CLINICAL IMPLICATIONS}

- Stalkers are most likely to be found among the diagnostic classes of psychotic disorders or (severe) personality disorders.

- Treatment of these behavioural problems should target the specific underlying psychopathological mechanisms, which require careful diagnostic assessment.

Both stalkers and victims are in urgent need of the development of specific treatments; treatments for stalkers will also benefit victims.

\section{LIMITATIONS}

- Few methodologically sophisticated studies have been conducted on stalking.

- Most of the available data are based on forensic cases and/or erotomania research and are probably not representative of the wide spectrum of stalking cases.

- Most of the evidence originates from North America; data specific to the European situation are lacking.

J. H. KAMPHUIS, PhD, P. M. G. EMMELKAMP, PhD, Department of Clinical Psychology, University of Amsterdam, The Netherlands

Correspondence: J. H. Kamphuis, University of Amsterdam Clinical Psychology, Roetersstraat I5, 1018 WB Amsterdam, The Netherlands. Tel: 020-5256785; fax: 020-6391369; e-mail:

kp.kamphuis@macmail.psy.uva.nl

(First received 22 July 1999, final revision 30 September 1999, accepted I October 1999)

_ (1998) The Psychology of Stalking: Clinical and Forensic Perspectives. San Diego, CA: Academic Press.

_ \& Gothard, S. (1995) Demographic and clinical comparison of obsessional followers and offenders with mental disorders. American Journal of Psychiatry, 152, $258-263$.

Mullen, P. E. \& Pathé, M. (1994) The pathologica extensions of love. British Journal of Psychiatry, $\mathbf{1 6 5}$ 614-623.

_, Pathé, M., Purcell, R., et al (1999) Study of stalkers. American Journal of Psychiatry, 156, 1244-1249.

Pathé, M. \& Mullen, P. E. (1997) The impact of stalker on their victims. British Journal of Psychiatry, 170, 12-17.

_ , _ \& Purcell, R. (1999) Stalking: false claims of victimisation. British Journal of Psychiatry, 174, 170-172.

Romans, J. S. C., Hays, M. J. R. \& White, T. K. (1996) Stalking and related behaviours experienced by counseling center staff members from current or former clients. Professional Psychology: Research and Practice, 27 595-599.

Tjaden, P. \& Thoenness, N. (1997) Stalking in America: Findings from the National Violence against Women Survey. Denver, CO: Center for Policy Research.

Walker, L. E. \& Meloy, J. R. (1998) Stalking and domestic violence. In The Psychology of Stalking: Clinica and Forensic Perspectives (ed. J. R. Meloy), pp. 139-161. San Diego, CA: Academic Press.

Wilson, M. \& Daly, M. (1993) Spousal homicide risk and estrangement. Violence and Victims, 8, 3-16.

Wright, J. A. Burgess, A. G., Burgess, A.W., et al (1996) A typology of stalking. Journal of Interpersonal Violence, II, 487-502.

Zona, M. A., Sharma, K. K. \& Lane, J. C. (1993) A comparative study of erotomanic and obsessional subjects in a forensic sample. Journal of Forensic Sciences, 38. 894-903. 